\title{
Continual rehabilitation motivation of patients with postparalytic facial nerve syndrome
}

\author{
Maike Osthues $^{1} \cdot$ Anna-Maria Kuttenreich $^{1,2} \cdot$ Gerd Fabian Volk $^{1,2} \cdot$ Christian Dobel $^{1,2} \cdot$ Bernhard Strauss $^{3}$. \\ Uwe Altmann $^{3}$. Orlando Guntinas-Lichius ${ }^{1,2}$ (1)
}

Received: 26 February 2021 / Accepted: 18 May 2021 / Published online: 24 May 2021

(c) The Author(s) 2021

\begin{abstract}
Purpose To evaluate the continued rehabilitation motivation in patients with postparalytic facial synkinesis (PFS).

Methods In this single-center cross-sectional survey, the multidimensional patient questionnaire for assessment of rehabilitation motivation (PAREMO-20) was used to assess the rehabilitation motivation. Associations Sunnybrook and Stennert index grading, Facial Clinimetric Evaluation (FaCE) survey, general quality of life (SF-36), Liebowitz Social Anxiety Scale (LSAS), Patient Health Questionnaire (PHQ)-9, technology commitment and affinity, and interest in further therapy were analyzed. Results 69 adults with PFS (73\% women; median age: 54 years) answered the survey. In comparison to prior treatment forms, there was a significant higher future interest in computer-based home facial training $(p<0.0001)$. For PAREMO Psychological burden subscore, SF36 Emotional role was the highest negative correlative factor $(p<0.0001)$. For PAREMO Physical burden subscore, SF-36 General health was the highest negative correlative factor $(p=0.018)$. Working $(p=0.033)$ and permanent relationship $(p=0.029)$ were the only independent factors correlated to PAREMO Social Support Subscore. Higher positive impacts of technology affinity was inversely correlated to PAREMO Knowledge subscore $(p=0.017)$. Lower SF-36 Role physical subscore $p=0.045)$ and a lower SF-36 General health $(p=0.013)$ were correlated to a higher PAREMO Skepticism subscore.

Conclusions Patients with PFS seem to have a high facial motor and non-motor psychosocial impairment even after several facial therapies. Rehabilitation-related motivation increases with both, higher facial motor and non-motor dysfunction. Social and emotional dysfunction are drivers to be interested in innovative digital therapy forms.
\end{abstract}

Keywords Rehabilitation · Motivation · Facial nerve $\cdot$ Chronic facial palsy $\cdot$ Facial paralysis $\cdot$ Anxiety $\cdot$ Depression · Patient reported outcome measure $\cdot$ Quality of life

\section{Introduction}

Orlando Guntinas-Lichius

orlando.guntinas@med.uni-jena.de

1 Department of Otorhinolaryngology, Jena University Hospital, Friedrich-Schiller University Jena, Am Klinikum 1, 07747 Jena, Germany

2 Facial Nerve Center Jena, Jena University Hospital, Friedrich-Schiller University Jena, Am Klinikum 1, 07747 Jena, Germany

3 Institute of Psychosocial Medicine, Psychotherapy and Psycho-Oncology, Jena University Hospital, Jena, Germany
Severe facial nerve paralysis can lead in the chronic phase to altered patterns of muscle contraction and postparetic facial synkinesis (PFS). PFS is a disfiguring condition characterized by involuntary contraction of one or more facial muscles during voluntary movement of other muscles [1, 2]. Diminished facial expression, especially the inability to smile and affected face-to-face communication are the major non-motoric disabilities [3]. Altered facial motor function and the non-motor psychosocial problems can severely decrease quality of life in facial palsy patients [4]. Many patients with PFS are never referred to a specialist or with a too long delay to receive a treatment [5].

The patient's perspective on the demand of and access to therapy for PFS has also be considered. An effective 
rehabilitation is linked to the patient's motivation and compliance regarding the rehabilitation process [6, 7]. Physical rehabilitation therapy is the most often prescribed measure [8]. However, access to specific facial rehabilitation is limited. Complementary, patients with PFS are advised to carry out self-reliant home-based exercise programs [9]. However, these physiotherapeutic exercises are often performed incorrectly, not as frequently as recommended, or are stopped after a certain time [10]. Digital technology with web-based surveillance of the patients at home by facial therapy specialists could potentially improve the long-term continual access to therapy [11].

Recently, we performed a large cross-sectional survey to study the acceptance of emotion-sensitive training systems for patients with facial palsy. First results are published elsewhere [12]. The present study on the subgroup of patients with PFS was performed for better understanding the longterm rehabilitation motivation, expectations and its influencing factors. Patients with PFS were invited to complete a survey including validated patient-reported outcome measures on their rehabilitation motivation, motor and non-motoric facial dysfunction, quality of life, and technology affinity. We hypothesized that patients with higher motoric and nonmotoric dysfunctions have a higher and continuing motivation for long-term rehabilitation.

\section{Material and methods}

\section{Study design and inclusion criteria}

This study was part of a cross-sectional survey of adult patients with facial palsy (International Statistical Classification of Diseases and Related Health Problems, German Modification (ICD-10-GM) code: G51.0). These patients had visited the Department of Otolaryngology, Jena University Hospital, Germany, between 2006 and 2016 and had given written consent to be contacted of research purposes. 300 patients counting backwards from last contact with the department were contacted by post or directly in the department (Flowchart, see Supplement Fig. 1). 81 patients (response rate: $27 \%$ ) answered the questionnaire. The present study analyzed the data of the patients with (PFS) at the time of the survey. The criteria were as follows: (a) a unilateral peripheral facial palsy; (b) incomplete recovery, (c) interval between onset and assessment at least 6 months; (d) at least one facial electromyography (EMG) confirming a PFS including synkinetic activity between periocular and perioral facial muscles [1, 13]. 204 of the contacted 300 patients fulfilled these PFS criteria (69 answered, 135 did not answer; response rate of PFS patients: $33.8 \%$ ). Hence, these 69 patients with PFS constituted the opportunity sample. All facial palsy-related data were prospectively collected in the department and were complete for all 69 patients. The institutional review board of the Jena University Hospital approved the cross-sectional survey and the study protocol for the additional retrospective data analysis.

\section{Assessment with several patient-reported outcome measures}

Socio-demographic data were collected. Furthermore, questions were asked about initial treatment during the acute phase of the disease, prior treatment in the chronic phase of the disease and current most burden complaints. A list of therapy options was offered with the question to select therapy forms the patient would use like to continue or in be interested in. This list included standard therapy forms (Home mirror training, Facial training with therapist, biofeedback training, facial electrostimulation, acupuncture, light/heat/cold therapy), drugs (supportive eye protection with drops/ointment, botulinum toxin), surgery (nerve surgery, eye lid surgery, angle of the mouth surgery), and also the newer technology allowing a computer-based home training [14]. Finally, we offered the implantation of a potentially in the future available facial pace maker [15]. All therapy forms were shortly explained. User preferences regarding a described concept of an emotion-sensitive training system and sleep quality of the patients were also recorded and published elsewhere [12]. The survey covered several validated patient-reported outcome measures (PROMs). The patient questionnaire for assessment of rehabilitation motivation (PAREMO-20) was used as primary outcome parameter. PAREMO-20 is a multidimensional instrument to determine the general rehabilitation-related motivation of the patients $[16,17]$. PAREMO-20 consists of 20 items forming six subscales: "psychological burden", "physical burden", "social support","readiness to change", "knowledge", and "skepticism". Answers are given on a 4-point Likert scale. Higher values on subscales indicate higher rehabilitation motivation except for the subscale "skepticism". Here, higher scores indicate lower rehabilitation motivation. General quality of life was measured using the 36-item SF-36 Health Survey [18]. Higher scores indicate higher quality of life. The Facial Clinimetric Evaluation (FaCE) scale was used to measure the facial palsy-related quality of life $[19,20]$. The FaCE has six independent domains: social function, facial movement, facial comfort, oral function, eye comfort, lacrimal control, and a total core incorporating all domains. Using a specific formula, a score from 0 (worst) to 100 (best) is calculated. The 24-item Liebowitz Social Anxiety Scale (LSAS), uses two subscales that address social interaction (11 items) and performance (13 items), measuring an individual's fear and avoidance of social situations over the past week. Answers are given on a 4-point Likert scale [21]. The German version of patients' health questionnaire (PHQ-D) was used 
to record depression symptoms [22]. With nine items, the DSM-IV criteria for depression are asked on a 4-point Likert scale. Higher LSAS or PHQ-D scores indicate higher social anxiety or higher depression levels, respectively. Finally, the survey included the questionnaire for technical commitment [23]. The questionnaire consists of 12 items using a 5-point Likert scale to record in subitems "technology acceptance", "technology competence", "technology control beliefs", and "technology willingness". Finally, the Technology Affinity questionnaire-attitude to and handling of electronic devices (TA-EG), was used to understand the patient's interest, experience and trust in technology [24]. The instrument comprised 19 items covering 4 subscales and uses a 5-point Likert scale: "enthusiasm for technology", "competence in dealing with technology", its "positive consequences", and "negative consequences". Higher technical commitment subscore and higher TA-EG subscores, respectively, indicate a higher agreement.

\section{Facial grading}

Additionally to self-ratings of facial palsy-related quality of life (with $\mathrm{FaCE}$ ), facial motor function grading was performed using the Stennert index and the Sunnybrook Facial Grading Scale [25, 26]. The Stennert index was used because of its popularity in Germany. It was also used to classify the initial facial function at first presentation in the hospital. The observer judges facial symmetry at rest in four regional categories $(0=$ normal resting tone/symmetry up to $4=$ no resting tone/gross asymmetry) and the motility of the facial muscles in six regional categories $(0=$ normal motility up to $6=$ complete paralysis). The total score of the Stennert index summarizes both subscores. The Sunnybrook Facial Grading Scale was used because of its international recognition and because it allowed a separate classification of the degree of synkinesis. The Sunnybrook Facial Grading Scale is a regional weighted system that rates three subscores: resting symmetry, the degree of voluntary facial muscle movement, and involuntary muscle contraction (synkinesis). The three subscores are used to calculate a composite score $(0=$ total paralysis; $100=$ normal function).

\section{Statistics}

All outcome variables were analyzed with IBM SPSS statistics software (Version 25; IBM. New York) for medical statistics. Data are presented as frequencies or mean \pm standard deviation (SD) if not otherwise indicated. To investigate selection bias we compared the data of patients who answered the questionnaire with the patients not responding. Pearson's chi-square test was used for nominal data and the Mann-Whitney $U$ test for metric data. McNemar test was used to compare binominal data of facial therapy types received in the past to future interests. Predictors for future interest in computer-based home therapy were explored using chi-square test for nominal data and Mann-Whitney $U$ test for metric data. Predictors for the rehabilitation motivation were explored using Spearman's correlation of PAREMO-20 subscales and all other parameters, e.g. social anxiety score. Comparisons of subgroups were only performed if a subgroup contained $\geq 10$ patients. Linear regression analyses including parameters from univariate analysis and $p<0.05$ were performed to evaluate associations related to the PAREMO-20 subscales. The significance level was set at $p<0.05$.

\section{Results}

\section{Investigation of a selection bias: comparison of study participants with the patients not responding to the survey}

Sixty-nine patients with PFS answered the survey. 135 patients did not answer. The comparison of both groups is summarized in Supplement Table 1. The study participants performed more frequently facial exercises at home $(p<0.0001)$, had more therapy with a therapist $(p<0.0001)$, and received more frequently botulinum toxin injections $(p=0.003)$. Gender distribution, age, and initial severity of the palsy were not different between both groups (all $p>0.05)$. Related to the Stennert index in motion and total index, improvement of the palsy from onset to time of the survey was better for non-participants $(p=0.008 ; p=0.023$, respectively). The composite score of the Sunnybrook grading revealed a lower score (worse function) for study participants $(p=0.022)$.

\section{Baseline characteristics, socioeconomic data, motor and non-motor deficits, and interest in further therapy types of the study participants}

Median age of the participants was 54 years. Most patients were females (72.5\%). Median onset of facial palsy was 2.6 years ago. More details are shown in Table 1. Nearly all patients had performed mirror training at home (94.2\%) or reported a prior specific facial training with a therapist (82.6\%). All patients had a therapy form in direct contact with a therapist. The median number of different types of facial therapy (eye protection excluded) was 4 (range: 1-7). Other frequent therapies in the chronic phase of the disease were as follows: continued eye protection (85.5\%), acupuncture (49.3\%), electrostimulation (44.0\%), and physical therapy with cold, heat or light $(40.6 \%)$. The three most often mentioned still disturbing symptoms were as follows: Impaired eye closure (66.7\%), asymmetric face (63.8\%), and 
Table 1 Patients' characteristics and socioeconomic data $(N=69)$

\begin{tabular}{|c|c|c|}
\hline Parameter & Absolute & $\%$ \\
\hline \multicolumn{3}{|l|}{ Gender } \\
\hline Female & 50 & 72.5 \\
\hline Male & 19 & 27.5 \\
\hline \multicolumn{3}{|l|}{ Permanent relationship } \\
\hline No & 14 & 20.3 \\
\hline Yes & 55 & 79.7 \\
\hline \multicolumn{3}{|l|}{ Profession } \\
\hline Employed & 41 & 59.4 \\
\hline Retired & 19 & 27.5 \\
\hline Unemployed & 7 & 10.1 \\
\hline In apprentice/studying & 2 & 2.9 \\
\hline \multicolumn{3}{|l|}{ Highest education } \\
\hline Secondary school & 26 & 37.7 \\
\hline High school & 12 & 17.4 \\
\hline University & 29 & 42.0 \\
\hline Other & 2 & 2.9 \\
\hline \multicolumn{3}{|c|}{ Previous therapy in chronic phase of the disease } \\
\hline Home mirror training & 65 & 94.2 \\
\hline Supportive eye protection* & 59 & 85.5 \\
\hline Facial training with therapist & 57 & 82.6 \\
\hline Acupuncture & 34 & 49.3 \\
\hline Electrostimulation & 32 & 46.2 \\
\hline Biofeedback training & 31 & 44.0 \\
\hline Light/heat/cold therapy & 28 & 40.6 \\
\hline Facial training with computer & 20 & 29.0 \\
\hline Eye lid surgery & 14 & 20.3 \\
\hline Botulinum toxin & 18 & 26.1 \\
\hline Angle of mouth surgery & 2 & 2.9 \\
\hline \multicolumn{3}{|l|}{ Still most disturbing symptoms } \\
\hline Impaired/uncontrolled eye closure & 46 & 66.7 \\
\hline Asymmetric face & 44 & 63.8 \\
\hline Impaired smiling & 36 & 52.2 \\
\hline Decreased tearing & 17 & 24.6 \\
\hline \multirow[t]{2}{*}{ Increased tearing } & 8 & 11.6 \\
\hline & Mean \pm SD & Median, range \\
\hline Age, years & $50.4 \pm 14.2$ & $54,20-76$ \\
\hline Interval onset to survey, months & $5.9 \pm 9.1$ & $2.6,0.5-60.6$ \\
\hline Stennert index, at rest & $1.1 \pm 1.3$ & $1,0-4$ \\
\hline Stennert index, in motion & $3.3 \pm 1.6$ & $3,1-6$ \\
\hline Stennert index, total & $4.4 \pm 2.8$ & $4,1-10$ \\
\hline Sunnybrook, composite & $44.8 \pm 20.5$ & 41, 4-97 \\
\hline
\end{tabular}

$S D$ Standard deviation

*Eye drops, ointment, watch glass

impaired smiling (52.2\%). Stennert index and Sunnybrook grading confirmed the still affected facial motor function: Median total Stennert index and composite score of the Sunnybrook index were 4 and 41, respectively. This corresponded to patient's self-reported facial function (Table 2):
The FaCE Facial movement subscore was the lowest with a median value of 33.0, followed by the FaCE Facial comfort subscore (median: 50.0), and the FaCE Eye comfort subscore (median: 62.5). From the SF-36 subscores, SF-36 Vitality (median: 55.0), and SF-36 General health (median: 57.0) showed the worst results. LSAS and PHQ-9 showed a significant impairment in the study group. Technical commitment and technology affinity to electronic devices was moderate.

All patients showed interest in further therapy (Supplement Table 2), mostly in the form of home mirror therapy $(84.1 \%)$, continual eye protection $(82.6 \%)$, facial training with therapist $(72.5 \%)$, with a computer $(55.1 \%)$, and biofeedback therapy (42.0\%). Compared to the past, the future interest in home facial mirror training, acupuncture, electrostimulation, and any light/heat/cold therapy decreased significantly (all $p<0.05$; Fig. 1 ), while the interest in computer-assisted home facial training increased significantly $(\mathrm{p}<0.0001)$. Therefore, factors with association with this wish were further explored (Supplement Table 3). Patients with future interest in computer-assisted facial therapy showed a lower FaCE Eye comfort subscore $(p=0.044)$, lower SF-36 Vitality subscore $(p=0.008)$, lower SF-36 Social functioning $(p=0.009)$, lower SF-36 Role functioning $(p=0.010)$, lower SF-36 Mental health $(p=0.005$, leading also to a lower SF-36 Mental summary score $(p=0.002)$.

\section{Rehabilitation motivation domains and influencing factors}

Table 2 lists the results of the PAREMO-20 subscores. The two highest scores were the Physical burden subscore (median: 10) and the Knowledge subscore (median: 9). The PAREMO-20 subscores Psychological burden, Physical burden, and Readiness to change showed the highest bivariate correlation to each other (Supplement Table 4). The correlations between the six PAREMO-20 subscores and patients' characteristics and the other assessments did not show a uniform picture (Supplement Table 5).

Most relevant correlations $(r>0.5)$ were seen between low FaCE Social function, or low FaCE Total score versus high Psychological burden or Physical burden subscore. Several SF-36 subscores and the LSAS subscores were negatively correlated with Psychological burden or Physical burden subscore. The SF-36 General health or SF-36 Vitality domain also correlated with Readiness to change subscore. PHQ-9 was negatively correlated to Psychological burden, Physical burden or Readiness to change subscore. Technology commitment, technology affinity, facial grading, or the therapy interests of the patients did not show any high correlation.

The results of the multivariate linear regression analyses for independent associations to the PAREMO-20 
Table 2 Results of the questionnaires $(N=69)$

\begin{tabular}{|c|c|c|}
\hline & Mean \pm SD & Median, range \\
\hline \multicolumn{3}{|l|}{ Facial Clinimetric Evaluation Scale (FaCE) } \\
\hline FaCE Facial movement & $38.1 \pm 21.6$ & $33.3,0-91.7$ \\
\hline FaCE Facial comfort & $50.5 \pm 26.3$ & $50.0,0-100$ \\
\hline FaCE Oral function & $76.1 \pm 25.3$ & $87.5,0-100$ \\
\hline FaCE Eye comfort & $57.7 \pm 31.9$ & $62.5,0-100$ \\
\hline FaCE Lacrimal control & $68.8 \pm 29.5$ & $75.0,0-100$ \\
\hline FaCE Social function & $64.7 \pm 27.5$ & $68.6,0-100$ \\
\hline FaCE Total score & $57.1 \pm 16.5$ & $60.0,13.3-92.9$ \\
\hline \multicolumn{3}{|l|}{ 36-Item Short Form Survey (SF-36) } \\
\hline SF-36 Physical functioning & $83.4 \pm 22.8$ & $90.0,5-100$ \\
\hline SF-36 Role physical & $64.7 \pm 39.4$ & $75.0,0-100$ \\
\hline SF-36 Bodily pain & $70.5 \pm 27.1$ & $74.0,0-100$ \\
\hline SF-36 General health & $58.0 \pm 23.9$ & $57.0,10-100$ \\
\hline SF-36 Vitality & $54.1 \pm 20.3$ & $55.0,10-100$ \\
\hline SF-36 Social role functioning & $69.9 \pm 26.6$ & $75.0,0-100$ \\
\hline SF-36 Emotional role functioning & $66.5 \pm 42.7$ & $100.0,0-100$ \\
\hline SF-36 Mental health & $66.8 \pm 19.5$ & $68.0,16-96$ \\
\hline SF-36 Physical health sum score & $47.4 \pm 9.6$ & $48.9,23.3-58.7$ \\
\hline SF-36 Mental health sum score & $44.6 \pm 12.6$ & $46.9,18.7-66.8$ \\
\hline \multicolumn{3}{|l|}{ Liebowitz Social Anxiety Scale (LSAS) } \\
\hline LSAS Anxiety & $43.4 \pm 15.8$ & $40.8,24-96$ \\
\hline LSAS Avoidance & $44.7 \pm 14.9$ & $41.7,24-96$ \\
\hline LSAS Total & $87.8 \pm 30.1$ & $82.0,48-192$ \\
\hline Patient Health Questionnaire (PHQ)-9 & $5.8 \pm 4.9$ & $4,0-20$ \\
\hline \multicolumn{3}{|l|}{ Technical commitment } \\
\hline Technology acceptance & $2.9 \pm 0.5$ & $2.8,1.8-4.0$ \\
\hline Technology competence & $3.0 \pm 0.6$ & $3.0,1.3-4.0$ \\
\hline Technology control beliefs & $2.8 \pm 0.7$ & $2.8,1.0-4.8$ \\
\hline Technology willingness & $2.9 \pm 0.5$ & $3.0,1.4-3.7$ \\
\hline \multicolumn{3}{|l|}{ Technology affinity to electronic devices } \\
\hline Enthusiasm & $3.0 \pm 0.9$ & $3.0,1.0-5.0$ \\
\hline Subjective competency & $3.4 \pm 0.8$ & $3.3,1.0-5.0$ \\
\hline Negative impacts & $2.6 \pm 0.5$ & $2.6,1.6-3.8$ \\
\hline Positive impacts & $3.1 \pm 0.6$ & $3.1,2.0-4.5$ \\
\hline \multicolumn{3}{|l|}{ PAREMO-20 } \\
\hline Psychological burden & $6.1 \pm 2.6$ & $5,3-12$ \\
\hline Physical burden & $9.6 \pm 3.9$ & $10,4-16$ \\
\hline Social support & $8.6 \pm 3.5$ & $8,4-16$ \\
\hline Readiness to change & $5.8 \pm 2.7$ & $6,3-12$ \\
\hline Knowledge & $9.0 \pm 2.7$ & $9,3-12$ \\
\hline Skepticism & $7.1 \pm 2.5$ & $7.5,3-12$ \\
\hline
\end{tabular}

PAREMO Questionnaire for patient rehabilitation motivation subscores are shown in Table 3. For the Psychological burden subscore, SF36 Emotional role was the highest negative correlative factor (beta $=-0.026 ; 95 \%$ confidence interval $[95 \% \mathrm{CI}]=-0.040$ to $-0.012 ; p<0.0001)$. For the Physical burden subscore, SF-36 General health was the highest negative correlative factor (beta $=-0.048 ; 95 \%$ $\mathrm{CI}=-0.088$ to $-0.009 ; p=0.018$ ). Working $($ beta $=2.149$;
$95 \% \mathrm{CI}=0.184$ to $4.114 ; p=0.033)$ and a steady relationship (beta $=1.823 ; 95 \% \mathrm{CI}=0.192$ to $3.453 ; p=0.029$ ) predicted the Social Support Subscore. A predictor for readiness for change was not found. Younger age was associated with a higher Knowledge subscore (beta $=-0.070$; 95\% $\mathrm{CI}=-0.125$ to $-0.015 ; p=0.013)$. Higher positive impacts of technology affinity was correlated to lower Knowledge 

future interests in different facial therapy types (red) to performed therapy in the past (blue). Calculations via McNemar test: $*=p<0.05$; $* * *=p<0.001$
Fig. 1 Comparison between

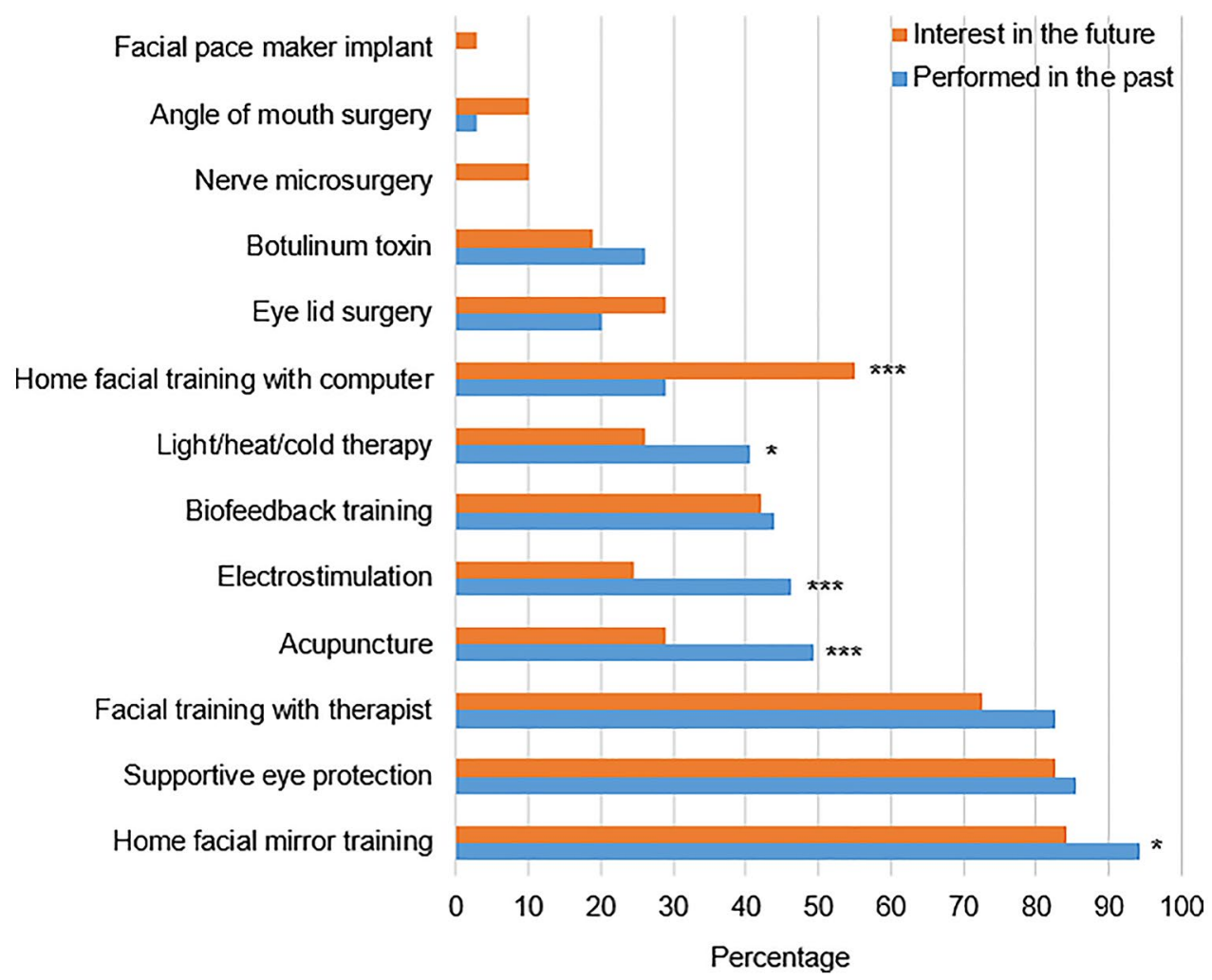

subscore (beta $=-1.700 ; 95 \% \mathrm{CI}=-3.082$ to -0.317 ; $p=0.017$ ). Finally, a lower SF-36 Role physical subscore (beta $=-0.023 ; 95 \% \mathrm{CI}=-0.046$ to $-0.001 ; p=0.045$ ) and a lower SF-36 General health (beta $=-0.038,95 \%$ $\mathrm{CI}=-0.067$ to $-0.008 ; p=0.013$ ) were correlated to a higher Skepticism subscore.

\section{Discussion}

The motivation of further rehabilitation of patients with PFS is an under-researched topic. The presented cohort still showed after a median time of 2.6 years after onset of the palsy a relevant facial motor and non-motor dysfunction. The reduced quality of life values (SF-36, FaCE) are within the range of prior studies. The reported values for LSAS and PHQ-9 are much higher in patients with PFS than in the normal population [19, 27-30]. The study group represents a selection of patients referred to a specialist center. All participants already had in the chronic phase of the disease at least one of internationally accepted types of non-surgical facial therapy [11,31]. Additionally, nearly all patients performed a supplementary facial training at home.

In general, the access to a specialized therapist is limited [11]. The efficacy of any facial training is related to the duration of each session and frequency [31]. Therefore, facial therapy for patients with PFS is normally combined with home training [31]. Patient's adherence to such a home training was not sufficiently investigated so far, but patients' barriers are known: fitting exercises into daily life, use of a mirror, and lack of regular feedback by a therapist [11]. These might be reasons why the motivation to perform a classical home training in the future was much lower in the present study in comparison to the frequent use in the past. Instead, there was a significant the interest in home computer-based facial training. The discussion about such training forms including telerehabilitation is gaining an entirely new significance by the COVID-19 pandemic [32]. A previous analysis had already shown that the patients with facial palsy would find it very attractive to perform in the future facial therapy with an emotion-sensitive training system. Like in the present study, patients with more severe impairment of facial expression and psychosocial impairment rated significantly higher acceptance with such innovative systems [12].

The focus of this paper was to investigate the different dimensions of the patients' rehabilitation motivation. Using the PAREMO-20, the motivation dimensions Physical Burden, Social Support, and Knowledge were still high in our study collective even after long duration of PFS and much experience with standard facial therapy types. PAREMO data for the acute phase of facial palsy or data for any other directly comparable disease do not exist so far. The values in the Physical Burden, Social Support, and Knowledge dimensions were nearly as high as reported directly after herniated disc surgery 
Table 3 Multivariate linear regression analysis for independent associations with the PAREMO-20 subscores

\begin{tabular}{|c|c|c|c|c|c|}
\hline Measure & Beta & $\begin{array}{l}95 \% \mathrm{CI} \\
\text { lower }\end{array}$ & $\begin{array}{l}95 \% \mathrm{CI} \\
\text { upper }\end{array}$ & $\begin{array}{l}\text { Stand.* } \\
\text { beta }\end{array}$ & $p^{* *}$ \\
\hline \multicolumn{6}{|l|}{ PAREMO-20 Psychological burden } \\
\hline \multicolumn{6}{|l|}{ PROMs $; R^{2}=0.850 ; p<0.0001$} \\
\hline FaCE Facial comfort & -0.007 & -0.023 & 0.009 & -0.068 & 0.410 \\
\hline FaCE Eye comfort & -0.014 & -0.028 & -0.001 & -0.177 & 0.042 \\
\hline FaCE Social function & -0.013 & -0.037 & 0.011 & -0.135 & 0.294 \\
\hline SF-36 Role physical & 0.015 & 0.001 & 0.029 & 0.229 & 0.041 \\
\hline SF-36 Bodily pain & $-2 \mathrm{E}-05$ & -0.021 & 0.021 & 0.000 & 0.998 \\
\hline SF-36 General health & -0.018 & -0.039 & 0.002 & -0.170 & 0.080 \\
\hline SF-36 Vitality & 0.043 & 0.004 & 0.082 & 0.343 & 0.032 \\
\hline SF-36 Social role functioning & -0.011 & -0.041 & 0.019 & -0.116 & 0.461 \\
\hline SF-36 Emotional role functioning & -0.026 & -0.040 & -0.012 & -0.438 & $<0.0001$ \\
\hline SF-36 Mental health & -0.041 & -0.092 & 0.009 & -0.313 & 0.108 \\
\hline LSAS Anxiety & 0.017 & -0.048 & 0.083 & 0.105 & 0.602 \\
\hline LSAS Avoidance & -0.029 & -0.102 & 0.045 & -0.166 & 0.435 \\
\hline PHQ-9 & 0.133 & -0.026 & 0.293 & 0.250 & 0.100 \\
\hline \multicolumn{6}{|l|}{ PAREMO-20 Physical burden } \\
\hline \multicolumn{6}{|c|}{ Socioeconomic aspects; $R^{2}=0.326 ; p=0.025$} \\
\hline Age, years & 0.062 & -0.003 & 0.126 & 0.227 & 0.062 \\
\hline Relationship $(0=$ no; $1=$ yes $)$ & 1.770 & -0.503 & 4.043 & 0.186 & 0.125 \\
\hline \multicolumn{6}{|l|}{ PROMs $; R^{2}=0.768 ; p<0.0001$} \\
\hline FaCE Facial comfort & -0.030 & -0.063 & 0.003 & -0.204 & 0.073 \\
\hline FaCE Oral function & 0.022 & -0.066 & 0.110 & 0.144 & 0.616 \\
\hline FaCE Eye comfort & -0.029 & -0.055 & -0.003 & -0.246 & 0.027 \\
\hline FaCE Lacrimal control & -0.017 & -0.094 & 0.061 & -0.118 & 0.669 \\
\hline FaCE Social function & -0.024 & -0.078 & 0.029 & -0.175 & 0.365 \\
\hline SF-36 Physical functioning & -0.013 & -0.063 & 0.036 & -0.079 & 0.594 \\
\hline SF-36 Role physical & 0.009 & -0.022 & 0.039 & 0.087 & 0.577 \\
\hline SF-36 Bodily pain & 0.004 & -0.037 & 0.046 & 0.029 & 0.842 \\
\hline SF-36 General health & -0.048 & -0.088 & -0.009 & -0.300 & 0.018 \\
\hline SF-36 Vitality & -0.003 & -0.078 & 0.072 & -0.015 & 0.940 \\
\hline SF-36 Social role functioning & -0.045 & -0.111 & 0.020 & -0.314 & 0.173 \\
\hline SF-36 Emotional role functioning & 0.000 & -0.028 & 0.027 & -0.002 & 0.990 \\
\hline SF-36 Mental health & 0.010 & -0.086 & 0.105 & 0.049 & 0.840 \\
\hline LSAS Anxiety & -0.039 & -0.164 & 0.086 & -0.160 & 0.534 \\
\hline LSAS Avoidance & 0.028 & -0.112 & 0.168 & 0.110 & 0.686 \\
\hline PHQ-9 & 0.020 & -0.283 & 0.323 & 0.025 & 0.896 \\
\hline \multicolumn{6}{|l|}{ PAREMO-20 Social support } \\
\hline \multicolumn{6}{|c|}{ Socioeconomic aspects; $R^{2}=0.438 ; p=0.003$} \\
\hline Gender $(0=$ male; $1=$ female $)$ & -1.724 & -3.468 & 0.020 & -0.220 & 0.053 \\
\hline Relationship $(0=$ no; $1=$ yes $)$ & 2.149 & 0.184 & 4.114 & 0.247 & $\mathbf{0 . 0 3 3}$ \\
\hline Working $(0=$ no; $1=$ yes $)$ & -1.823 & -3.453 & -0.192 & -0.252 & 0.029 \\
\hline \multicolumn{6}{|l|}{ PROMs; $R^{2}=0.569 ; p=0.028$} \\
\hline FaCE Eye comfort & -0.008 & -0.037 & 0.021 & -0.073 & 0.578 \\
\hline FaCE Social function & -0.017 & -0.070 & 0.036 & -0.128 & 0.531 \\
\hline SF-36 Physical functioning & -0.038 & -0.090 & 0.014 & -0.243 & 0.147 \\
\hline SF-36 Role physical & -0.007 & -0.041 & 0.028 & -0.073 & 0.703 \\
\hline SF-36 Bodily pain & -0.009 & -0.054 & 0.035 & -0.072 & 0.669 \\
\hline SF-36 General health & -0.042 & -0.086 & 0.003 & -0.277 & 0.065 \\
\hline SF-36 Vitality & -0.012 & -0.097 & 0.073 & -0.069 & 0.779 \\
\hline SF-36 Social role functioning & 0.016 & -0.053 & 0.085 & 0.120 & 0.646 \\
\hline
\end{tabular}


Table 3 (continued)

\begin{tabular}{|c|c|c|c|c|c|}
\hline Measure & Beta & $\begin{array}{l}95 \% \mathrm{CI} \\
\text { lower }\end{array}$ & $\begin{array}{l}95 \% \text { CI } \\
\text { upper }\end{array}$ & $\begin{array}{l}\text { Stand.* } \\
\text { beta }\end{array}$ & $p^{* *}$ \\
\hline SF-36 Mental health & 0.056 & -0.047 & 0.159 & 0.306 & 0.281 \\
\hline LSAS Anxiety & -0.004 & -0.144 & 0.136 & -0.017 & 0.957 \\
\hline LSAS Avoidance & 0.048 & -0.110 & 0.206 & 0.198 & 0.548 \\
\hline PHQ-9 & 0.058 & -0.282 & 0.398 & 0.079 & 0.733 \\
\hline \multicolumn{6}{|l|}{ Facial grading } \\
\hline Stennert index, at rest, initial & -0.455 & -2.438 & 1.529 & -0.178 & 0.648 \\
\hline Stennert index, in motion, initial & 1.071 & -0.476 & 2.617 & 0.523 & 0.171 \\
\hline Stennert index, at rest & 1.102 & -0.797 & 3.002 & 0.406 & 0.250 \\
\hline Stennert index, in motion & -0.751 & -2.258 & 0.755 & -0.336 & 0.322 \\
\hline Sunnybrook, composite & -0.001 & -0.076 & 0.075 & -0.004 & 0.986 \\
\hline \multicolumn{6}{|l|}{ PAREMO-20 Readiness to change } \\
\hline \multicolumn{6}{|l|}{ PROMs $; R^{2}=0.699 ; p<0.0001$} \\
\hline FaCE Social function & 0.002 & -0.032 & 0.036 & 0.022 & 0.900 \\
\hline SF-36 Physical functioning & -0.009 & -0.044 & 0.026 & -0.079 & 0.598 \\
\hline SF-36 Role physical & -0.002 & -0.024 & 0.020 & -0.035 & 0.833 \\
\hline SF-36 Bodily pain & 0.002 & -0.027 & 0.030 & 0.017 & 0.909 \\
\hline SF-36 General health & -0.027 & -0.055 & 0.002 & -0.239 & 0.067 \\
\hline SF-36 Vitality & 0.010 & -0.045 & 0.065 & 0.074 & 0.727 \\
\hline SF-36 Social role functioning & -0.006 & -0.052 & 0.040 & -0.060 & 0.794 \\
\hline SF-36 Emotional role functioning & -0.017 & -0.038 & 0.003 & -0.279 & 0.093 \\
\hline SF-36 Mental health & -0.038 & -0.108 & 0.031 & -0.281 & 0.276 \\
\hline LSAS Anxiety & -0.027 & -0.118 & 0.064 & -0.160 & 0.556 \\
\hline LSAS Avoidance & 0.025 & -0.076 & 0.127 & 0.142 & 0.618 \\
\hline PHQ-9 & -0.004 & -0.223 & 0.216 & -0.007 & 0.972 \\
\hline \multicolumn{6}{|l|}{ Technology affinity; $R^{2}=0.199 ; p=0.267$} \\
\hline TA Subjective competency & -0.708 & -1.584 & 0.167 & -0.209 & 0.111 \\
\hline TA Positive impacts & 0.168 & -1.016 & 1.353 & 0.037 & 0.777 \\
\hline \multicolumn{6}{|l|}{ PAREMO-20 Knowledge } \\
\hline \multicolumn{6}{|c|}{ Socioeconomic aspects; $R^{2}=0.406 ; p=0.003$} \\
\hline Age, years & -0.070 & -0.125 & -0.015 & -0.363 & 0.013 \\
\hline Working $(0=$ no; $1=$ yes $)$ & 0.360 & -1.235 & 1.956 & 0.064 & 0.653 \\
\hline \multicolumn{6}{|c|}{ Prior therapy chronic phase; $R^{2}=0.460 ; p=0.002$} \\
\hline Facial training therapist & 2.441 & 0.683 & 4.200 & 0.328 & 0.007 \\
\hline Biofeedback training & 1.343 & -0.219 & 2.904 & 0.241 & 0.091 \\
\hline Facial training computer & 0.036 & -1.384 & 1.456 & 0.007 & 0.960 \\
\hline \multicolumn{6}{|l|}{ PROMs; $R^{2}=0.356 ; p=0.012$} \\
\hline FaCE Oral function & -0.033 & -0.097 & 0.031 & -0.301 & 0.313 \\
\hline FaCE Lacrimal control & 0.057 & 0.002 & 0.112 & 0.614 & 0.042 \\
\hline \multicolumn{6}{|c|}{ Technology affinity; $R^{2}=0.407 ; p=0.009$} \\
\hline TA Subjective competency & 0.499 & -0.387 & 1.386 & 0.139 & 0.265 \\
\hline TA Negative impacts & 0.697 & -0.483 & 1.876 & 0.144 & 0.242 \\
\hline TA Positive impacts & -1.700 & -3.082 & -0.317 & -0.288 & $\mathbf{0 . 0 1 7}$ \\
\hline \multicolumn{6}{|l|}{ Therapy interests; $R^{2}=0.512 ; p=0.002$} \\
\hline Facial training with therapist & 0.845 & -0.752 & 2.441 & 0.133 & 0.294 \\
\hline Facial training with computer & 1.743 & -0.131 & 3.616 & 0.332 & 0.068 \\
\hline Biofeedback training & 0.605 & -1.329 & 2.539 & 0.115 & 0.533 \\
\hline Botulinum toxin & 0.356 & -1.291 & 2.004 & 0.056 & 0.666 \\
\hline \multicolumn{6}{|l|}{ PAREMO-20 Skepticism } \\
\hline \multicolumn{6}{|l|}{ PROMs $; R^{2}=0.613 ; p=0.006$} \\
\hline FaCE Facial movement & -0.018 & -0.045 & 0.009 & -0.155 & 0.192 \\
\hline
\end{tabular}


Table 3 (continued)

\begin{tabular}{lrrrrr}
\hline Measure & Beta & $\begin{array}{l}\text { 95\% CI } \\
\text { lower }\end{array}$ & $\begin{array}{l}\text { 95\% CI } \\
\text { upper }\end{array}$ & $\begin{array}{l}\text { Stand.* } \\
\text { beta }\end{array}$ & $p^{* *}$ \\
\hline FaCE Facial comfort & -0.021 & -0.044 & 0.001 & -0.226 & 0.057 \\
FaCE Social function & -0.007 & -0.043 & 0.029 & -0.074 & 0.711 \\
SF-36 Physical functioning & -0.003 & -0.037 & 0.030 & -0.029 & 0.849 \\
SF-36 Role physical & -0.023 & -0.046 & -0.001 & -0.364 & $\mathbf{0 . 0 4 5}$ \\
SF-36 General health & -0.038 & -0.067 & -0.008 & -0.359 & $\mathbf{0 . 0 1 3}$ \\
SF-36 Vitality & 0.003 & -0.053 & 0.060 & 0.027 & 0.907 \\
SF-36 Social role functioning & 0.033 & -0.014 & 0.081 & 0.357 & 0.165 \\
SF-36 Mental health & 0.035 & -0.033 & 0.103 & 0.265 & 0.311 \\
LSAS Anxiety & 0.056 & -0.039 & 0.150 & 0.353 & 0.243 \\
LSAS Avoidance & -0.062 & -0.169 & 0.045 & -0.372 & 0.249 \\
PHQ-9 & 0.181 & -0.053 & 0.414 & 0.339 & 0.127 \\
\hline
\end{tabular}

PROM Patient-reported outcome measures, FaCE Facial Clinimetric Evaluation, SF Short Form, LSAS Liebowitz Social Anxiety Scale, $P H Q$ Patient Health Questionnaire, $T A$ Technology affinity

*Standardized beta

*** $p$-values $<0.05$ in bold

or for cardiological patients after surgery $[6,33]$. The Skepticism dimension was higher than reported for patients after acute surgery [33]. Probably, this reflects that our patients underwent already several rehabilitation therapies with insufficient success, at least less success than subjectively expected. The expressed interest in continual rehabilitation, especially in patients with prior experience with facial therapy with a therapist, higher physical burden, especially dysfunctional eye closure, make clear that new and additional therapy concepts have to be developed for a continual facial therapy. A possible solution could be the development and validation of home-based sensor-based digital technology at best in combination with a remote monitoring function for the involved therapist [11, $12,34]$. The subgroup of the patients with high psychosocial burden would probably profit from an integration of remotely communicated, therapist-delivered psychotherapy [35].

Although a good characterized sample was evaluated, the study has the typical limitations of a retrospective analysis. A selection bias beyond the per se selection of motivated patients seems to be negligible but cannot be ruled out. So far treatment of patients with PFS, whether classically faceto-face with a therapist or with any innovative home-based approaches, is mainly focused on facial motor disturbances. Next steps should address better integration of direct treatment of facial non-motoric disturbances into the treatment concepts for patients with PFS.

\section{Conclusions}

Postparalytic facial synkinesis (PFS) leads to persistent worse general and disease-specific quality of life as well as a continual interest in rehabilitation therapy beyond the second year after onset of the acute facial palsy. The patients show a high interest in innovative digital solutions for facial rehabilitation. The non-motoric facial dysfunctions enforce the rehabilitation motivation. Boosted by the pandemic, the future focus will be in home-based sensor-based digital technology solutions with remote monitoring by the facial therapist allowing frequent intensive training sessions. A combination with remote psychotherapy could be useful to threat also the high levels so social anxiety and depressions.

Supplementary Information The online version contains supplementary material available at https://doi.org/10.1007/s00405-021-06895-2.

Acknowledgements We thank Eva Miltner and Hendrik Möbius for their help with the data acquisition and their engagement in the Facial Nerve Center, Jena University Hospital, Germany.

Funding Open Access funding enabled and organized by Projekt DEAL. O.G.-L. acknowledges funding by a Deutsche Forschungsgemeinschaft (DFG) grant GU-463/12-1. U.A. and O.G.-L. acknowledge funding by the German Federal Ministry for Education and Research (BMBF) grant IRESTRA 16SV7209.

\section{Declarations}

Conflict of interest None of the authors has any conflict of interest to disclose.

Ethical approval We confirm that we have read the Journal's position on issues involved in ethical publication and affirm that this report is consistent with this guideline.

Open Access This article is licensed under a Creative Commons Attribution 4.0 International License, which permits use, sharing, adaptation, distribution and reproduction in any medium or format, as long as you give appropriate credit to the original author(s) and the source, 
provide a link to the Creative Commons licence, and indicate if changes were made. The images or other third party material in this article are included in the article's Creative Commons licence, unless indicated otherwise in a credit line to the material. If material is not included in the article's Creative Commons licence and your intended use is not permitted by statutory regulation or exceeds the permitted use, you will need to obtain permission directly from the copyright holder. To view a copy of this licence, visit http://creativecommons.org/licenses/by/4.0/.

\section{References}

1. Raslan A, Guntinas-Lichius O, Volk GF (2019) Altered facial muscle innervation pattern in patients with postparetic facial synkinesis. Laryngoscope 130(5):E320-E326

2. Volk GF, Thielker J, Moller MC et al (2020) Tolerability of facial electrostimulation in healthy adults and patients with facial synkinesis. Eur Archiv Otorhinolaryngol 277:1247-1253

3. Bradbury ET, Simons W, Sanders R (2006) Psychological and social factors in reconstructive surgery for hemi-facial palsy. $\mathrm{J}$ Plast Reconstr Aesthet Surg 59:272-278

4. van Veen MM, Quatela O, Tavares-Brito J et al (2019) Patientperceived severity of synkinesis reduces quality of life in facial palsy: a cross-sectional analysis in 92 patients. Clin Otolaryngol 44:483-486

5. Butler DP, Morales DR, Johnson K, Nduka C (2019) Facial palsy: when and why to refer for specialist care. Br J Gen Pract 69:579-580

6. Lobner M, Stein J, Luppa M et al (2017) Choosing the right rehabilitation setting after herniated disc surgery: motives, motivations and expectations from the patients' perspective. PLoS ONE 12:e183698

7. Zwingmann C, Moock J, Kohlmann T (2005) [Instruments for patient-reported outcomes and predictors in German-speaking rehabilitation research-current developments within the "Rehabilitation Sciences" research funding programme]. Rehabilitation 44:307-315

8. Lapidus JB, Lu JC, Santosa KB et al (2020) Too much or too little? A systematic review of postparetic synkinesis treatment. J Plast Reconstr Aesthet Surg 73:443-452

9. World Health Organization. WHO guidelines on health-related rehabilitation (rehabilitation guidelines). Available at: https:// www.who.int/disabilities/care/rehabilitation_guidelines_conce pt.pdf

10. Steiner B, Elgert L, Haux R, Wolf KH (2020) AGT-Reha-WK study: protocol for a non-inferiority trial comparing the efficacy and costs of home-based telerehabilitation for shoulder diseases with medical exercise therapy. BMJ Open 10:e036881

11. Szczepura A, Holliday N, Neville C et al (2020) Raising the digital profile of facial palsy: national surveys of patients' and clinicians' experiences of changing UK treatment pathways and views on the future role of digital technology. J Med Int Res 22:20406

12. Altmann U, Worrack S, Kaczmarek MC et al (2017) Acceptance of emotion-sensitive training systems of individuals suffering from facial paralysis and their relatives. Laryngorhinootol 96:380-387

13. Guntinas-Lichius O, Volk GF, Olsen KD et al (2020) Facial nerve electrodiagnostics for patients with facial palsy: a clinical practice guideline. Eur Arch Otorhinolaryngol 277:1855-1874

14. Volk GF, Finkensieper M, Guntinas-Lichius O (2014) EMG biofeedback training at home for patient with chronic facial palsy and defective healing. Laryngorhinootol 93:15-24

15. Jowett N, Kearney RE, Knox CJ, Hadlock TA (2019) Toward the bionic face: a novel neuroprosthetic device paradigm for facial reanimation consisting of neural blockade and functional electrical stimulation. Plast Reconstr Surg 143:62e-76e

16. Hafen K, Jastrebow J, Nubling R, Bengel J (2001) [Development of a patient questionnaire for assessment of motivation for rehabilitation(PAREMO)]. Rehabilitation 40:3-11

17. Nuebling R, Kriz D, Herwig J, Wirtz M, Fuchs S, Hafen K. Patientenfragebogen zur Erfassung der Reha-Motivation (PAREMO-20). Kurzmanual. Available at: https://www.psychologie.uni-freiburg. de/abteilungen/Rehabilitationspsychologie/downloads/PAREMO_ 20_Kurzmanual\%201\%20.pdf/ download. Accessed 2 Jan 2021

18. Ware JE Jr, Gandek B (1998) Overview of the SF-36 health survey and the International Quality of Life Assessment (IQOLA) project. JClinEpidemiol 51:903-912

19. Kahn JB, Gliklich RE, Boyev KP, Stewart MG, Metson RB, McKenna MJ (2001) Validation of a patient-graded instrument for facial nerve paralysis: the FaCE scale. Laryngoscope 111:387-398

20. Volk GF, Steigerwald F, Vitek P, Finkensieper M, Kreysa H, Guntinas-Lichius O (2015) [Facial disability index and facial clinimetric evaluation scale: validation of the German versions]. Laryngorhinootol 94:163-168

21. Liebowitz MR (1987) Anxiety. Mod Trends Pharmacopsychiatry 22:141-173

22. Kroenke K, Spitzer RL, Williams JB (2001) The PHQ-9: validity of a brief depression severity measure. J Gen Int Med 16:606-613

23. Neyer FJ, Felber J, Gebhardt C (2012) Development and validation of a brief measure of technology commitment. Diagnostica 58:87-99

24. Karrer K, Glaser C, Clemens C, Bruder C (2009) Technikaffinität erfassen - der Fragebogen TA-EGDer Mensch im Mittelpunkt technischer Systeme. 8. Berliner Werkstatt Mensch-MaschineSysteme. Düsseldorf: VDI Verlag GmbH

25. Stennert E, Limberg CH, Frentrup KP (1977) [An index for paresis and defective healing-an easily applied method for objectively determining therapeutic results in facial paresis (author's transl)]. HNO 25:238-245

26. Ross BG, Fradet G, Nedzelski JM (1996) Development of a sensitive clinical facial grading system. Otolaryngol Head Neck Surg 114:380-386

27. Volk GF, Granitzka T, Kreysa H, Klingner CM, Guntinas-Lichius O (2016) Nonmotor disabilities in patients with facial palsy measured by patient-reported outcome measures. Laryngoscope 126:1516-1523

28. Volk GF, Granitzka T, Kreysa H, Klingner CM, Guntinas-Lichius $\mathrm{O}$ (2016) Initial severity of motor and non-motor disabilities in patients with facial palsy: an assessment using patient-reported outcome measures. Eur Arch Otorhinolaryngol 274(1):45-52

29. Nellis JC, Ishii M, Byrne PJ, Boahene KDO, Dey JK, Ishii LE (2017) Association among facial paralysis, depression, and quality of life in facial plastic surgery patients. JAMA Facial Plast Surg 19:190-196

30. Morfeld M, Bullinger M, Nantke J, Brähler E (2005) Die Version 2.0 des SF-36 Health Survey-Ergebnisse einer bevölkerungsrepräsentativen Studie [The version 2.0 of the SF-36 Health Survey: results of a population-representative study]. Soz Praventivmed 50:292-300

31. Lindsay RW, Robinson M, Hadlock TA (2010) Comprehensive facial rehabilitation improves function in people with facial paralysis: a 5-year experience at the Massachusetts Eye and Ear Infirmary. Physical Ther 90:391-397

32. Ohlstein JF, Garner J, Takashima M (2020) Telemedicine in otolaryngology in the COVID-19 era: initial lessons learned. Laryngoscope 130:2568-2573

33. Lohss R, Blumenthal M, Gottschling-Lang A, Egen C, Gutenbrunner C, Sturm C (2018) [Determinants for the access to follow-up rehabilitation concerning cardiological patients after surgery]. Rehabilitation 57:85-91 
34. Watts P, Breedon P, Nduka C, Neville C, Venables V, Clarke S (2020) Cloud Computing Mobile Application for Remote Monitoring of Bell's Palsy. J Med Syst 44:149

35. Twomey C, O'Reilly G, Bültmann O, Meyer B (2020) Effectiveness of a tailored, integrative Internet intervention (deprexis) for depression: Updated meta-analysis. PLoS ONE 15(1):e0228100
Publisher's Note Springer Nature remains neutral with regard to jurisdictional claims in published maps and institutional affiliations. 